\title{
Ten-lump kinetic model for the two-stage riser catalytic cracking for maximizing propylene yield (TMP) process
}

\author{
Yupeng Du ${ }^{1} \cdot$ Qi Yang ${ }^{1}$ Chengtao Zhang ${ }^{2}$ Chaohe Yang ${ }^{1}$
}

Received: 20 May 2015/Accepted: 1 June 2015/Published online: 17 June 2015

(C) The Author(s) 2015. This article is published with open access at Springerlink.com

\begin{abstract}
Modeling Fluid Catalytic Cracking (FCC) riser reactors is of significance to FCC unit control, optimization and failure detection, as well as the development and design of new riser reactors. Under the guidance of catalytic reaction mechanisms and the demands for commercial production, a ten-lump kinetic model was developed for the TMP process in this study. The feedstock and products were divided into ten lumps by reasonably simplifying the reaction network, including heavy oil, diesel oil, gasoline olefins, gasoline aromatics, gasoline saturates, (butane + propane), butylene, propylene, dry gas and coke. Thirty-five sets of model parameters were estimated with the combined simulated annealing method and the damped least square method. The findings indicated that the model could predict the riser key products and their compositions quite well; thereby it could be useful to the production practice for the TMP process.
\end{abstract}

Keywords Riser reactor - Propylene $\cdot$ Lumped kinetics model $\cdot$ Parameter estimation

Yupeng Du

duzhan2005@126.com

$\triangle$ Chaohe Yang

yangch@upc.edu.cn

1 State Key Laboratory of Heavy Oil Processing, China University of Petroleum, Qingdao 266580, China

2 China Petroleum Engineering and Construction Corporation (Huadong Design Branch Company), Qingdao 266071, China

\section{Introduction}

Fluid Catalytic Cracking (FCC) serves as a key process in refining industry for converting heavy oil to valuable vehicle fuel such as gasoline and diesel. In recent decades, the role FCC plays in most refineries has been changing into converting low-value heavy oil into not only vehicle fuels but also more valuable light olefins to meet the increasing demand of ethylene and propylene worldwide. Related new technologies include ARGG process [1], FDFCC process [2], DCC process [3], MIP-CGP process [4], etc. High operation severity and/or multi-reaction zones are the common characteristics shared by these processes. However, high temperature and long residence time give rise to more dry gas produced and diesel hardly obtained [5]. Furthermore, it is quite difficult and uneconomical for a refinery to separate ethylene from dry gas. Thus, promoting propylene production without producing large amounts of dry gas by the FCC process is promising and challengeable. To this end, the two-stage riser catalytic cracking for maximizing propylene yield (TMP) process $[5,6]$ was developed at the China University of Petroleum under the support of the CNPC (China National Petroleum Corporation). TMP technology can significantly improve propylene yield and lower dry gas by featuring the following operations: relative lower temperature with larger ratio of catalyst-to-oil (RCO), stratified injections of various feedstocks, and proper contact time between catalyst and oil vapor. Indeed, these characteristics can enhance catalytic cracking and minimize thermal cracking [5]. Until now, TMP technology has been applied in four commercial FCC units.

Modeling description of riser reactors is of significance to maintaining the long period run, fault monitoring and operation optimization of FCC units [7, 8]. In mathematical

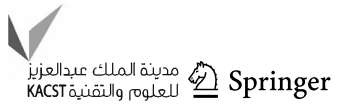


models for riser reactors, lumped kinetic models play an essential role $[9,10]$. However, investigations on kinetic models for the TMP process are scarce. Xu [11] developed a seven-lump kinetic model for heavy oil catalytic cracking based on microreactor experimental data, while Liu [12] proposed an eight-lump kinetic model for gasoline catalytic cracking according to microreactor experimental data. However, as for the TMP technology, catalytic reactions of both heavy oil and light hydrocarbons should be taken into consideration. Moreover, model parameters obtained based on microreactor experimental data should be modified with unit factors when the model is applied to industrial plants, which would weaken the theoretical property of the kinetic model. Although Guo [13] developed an eleven-lump kinetic model for the TMP process, only cracking reactions were considered in their model and a great many of important secondary reactions were neglected. What is more, using Guo's model, the propylene yield increases all the time when the conversion of heavy oil increases. Undoubtedly, it is not the case in real production, and it disobeys the cracking/pyrolysis mechanisms of hydrocarbons. For the purpose of solving these problems, a novel ten-lump kinetic model with veracity and practicality for the TMP process was developed in this investigation.

\section{Ten-lump kinetic model}

\section{Lumps and reaction network}

The TMP process is based on the two-stage riser FCC (TSRFCC) technology [6, 14]. The first stage of the riser deals with atmospheric residue and $\mathrm{C}_{4}$ mixture gas, whereas the second stage is fed with recycle oil and light gasoline, both coming from the first stage. The preferred reaction conditions for $\mathrm{C}_{4}$ mixture gas or light gasoline is high reaction temperature, high $\mathrm{RCO}$, and suitable residence time. However, for heavy oil, reaction temperature should be kept at low values to avoid excess reaction. In this technology, propylene, gasoline, and diesel are the desired products and the yield of the saturated LPG components should be minimized. Moreover, the gasoline should contain less olefins and more aromatics so as to present a high octane number. For the purpose of meeting the demand of prediction and analysis on the TMP process, the feedstock and products were divided into ten lumps during model development, including heavy oil, diesel, gasoline(olefins, aromatics and saturates), LPG (butane + propane, butylene and propylene), dry gas and coke according to their distillation ranges (see Table 1).

Generally, two kinds of reactions exist in the TMP process. The first one is the ideal reactions for producing goal products, including the cracking reactions in the
Table 1 Lumping of TMP reaction system

\begin{tabular}{llll}
\hline Lump no. & Lump symbol & Lump name & Distillation range \\
\hline A & HO & Heavy oil & $>350{ }^{\circ} \mathrm{C}$ \\
B & DO & Diesel oil & $204-350{ }^{\circ} \mathrm{C}$ \\
C & GO & Gasoline olefins & $\mathrm{C}_{5}-204^{\circ} \mathrm{C}$ \\
D & GA & Gasoline aromatics & $\mathrm{C}_{5}-204{ }^{\circ} \mathrm{C}$ \\
E & GS & Gasoline saturates & $\mathrm{C}_{5}-204{ }^{\circ} \mathrm{C}$ \\
F & $\mathrm{C}_{3,4}$ & Butane + propane & $\mathrm{C}_{4} \mathrm{H}_{10}+\mathrm{C}_{3} \mathrm{H}_{8}$ \\
G & $\mathrm{C}_{4=}$ & Butylene & $\mathrm{C}_{4} \mathrm{H}_{8}$ \\
$\mathrm{H}$ & $\mathrm{C}_{3=}$ & Propylene & $\mathrm{C}_{3} \mathrm{H}_{6}$ \\
$\mathrm{I}$ & $\mathrm{DG}$ & Dry gas & $\mathrm{C}_{2}+\mathrm{C}_{1}+\mathrm{H}_{2}$ \\
$\mathrm{~J}$ & $\mathrm{CK}$ & Coke & - \\
\hline
\end{tabular}

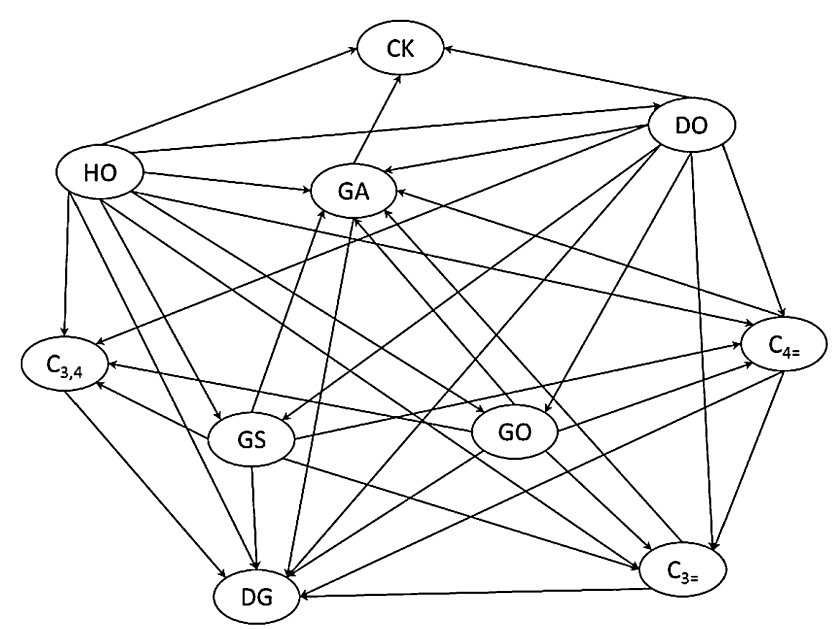

Fig. 1 Reaction network of the ten-lump kinetic model

carbonium ion mechanism, hydrogen transfer reactions, aromatization reactions and isomerization reactions. Another is the non-ideal reactions which produce byproducts (dry gas and coke). The non-ideal reactions include thermal cracking reactions in the free radical mechanism, alkylation and dimerization reactions, condensation reactions, dehydrogenation reactions and cokemake reactions. Neglecting small quantities of non-hydrocarbon compounds such as oxygen, sulfur or nitrogen, the reaction schemes between the ten lumps are shown in Fig. 1.

Many researchers have reported that the reaction order of distillates with wide boiling range is better be deemed as two since there is a large difference, in terms of the cracking ability, between different components in the distillate $[9,12]$. Therefore, reactions of converting heavy oil and diesel into light products were assumed to be secondorder irreversible reactions in the model, and the order of the rest reaction paths, except for reactions of butylene and propylene, was regarded as unit. As for the catalytic reactions of butylene and propylene, they follow the 
dimerization-cracking mechanism [15]. Therefore, secondorder was set for catalytic reactions of butylene and propylene.

\section{Mathematical model and parameter estimation}

To develop a mathematical model for this system, the following assumptions were introduced:

1. One-dimensional isothermal ideal plug flow reactor prevailed in the riser without radial and axial dispersion;

2. The density and heat capacities of all gaseous components were constant, the effects of the inert material were neglected;

3. Instantaneous vaporization occurred at the entrance of riser, and all cracking reactions were considered to take place in the riser reactor.

According to the reaction schemes shown in Fig. 1, the reaction rate $(R)$ of each lump involved in the reaction network was written, in the form of matrix, as:

$R=\frac{\mathrm{d} Y}{\mathrm{~d} t}=a \cdot \operatorname{RCO} \cdot K Y$,

where the reaction rate constants matrix $K$ is,
The first character in the subscript of each element in the matrix $K$ is the reactant, and the second character represents the product.

$Y$ is the vector of the weight fraction of each lump in the oil vapor:

$Y=\left(\begin{array}{llllllllll}y_{1}^{2} & y_{2}^{2} & y_{3} & y_{4} & y_{5} & y_{6} & y_{7}^{2} & y_{8}^{2} & y_{9} & y_{10}\end{array}\right)^{T}$.

The decay of the catalyst activity $(a)$ is represented by a function which depends on the amount of coke deposited on the catalysts [13]:

$a=\frac{1}{1+\frac{3.68 \mathrm{~N}}{100 \mathrm{RCO}}} \cdot \frac{1}{1+\frac{2.10 \mathrm{~A}_{\mathrm{h}}}{100 \mathrm{RCO}}} \cdot\left(1+14.36 C_{\mathrm{C}}\right)^{-0.20}$

where the values of deactivation constants $N$ and $A_{\mathrm{h}}$ are 0.10 and 22.64, respectively (data from Daqing atmospheric residue), and $C_{\mathrm{c}}$ is the coke concentration on the catalysts $\left(C_{\mathrm{c}}=y_{10} / \mathrm{RCO}\right)$.

In the mathematical model, differential equations were solved with forth-order Runge-Kutta method. The combined simulation annealing and Levenberg-Marquardt algorithm was employed for the optimization of the objective functions $\left(\sum_{i=1}^{12} \sum_{j=1}^{10}\left(y_{j, \text { cal }}-y_{j, \exp }\right)^{2}, y_{j, \text { cal }}\right.$ and $y_{j, \exp }$ are the calculated and experimental values of the yield of

$K=\left[\begin{array}{cccccccccc}-\sum_{j=2}^{10} k_{j i} & 0 & 0 & 0 & 0 & 0 & 0 & 0 & 0 & 0 \\ k_{\mathrm{A}-\mathrm{B}} & -\sum_{j=3}^{10} k_{j i} & 0 & 0 & 0 & 0 & 0 & 0 & 0 & 0 \\ k_{\mathrm{A}-\mathrm{C}} & k_{\mathrm{B}-\mathrm{C}} & -\sum_{j=4,6}^{9} k_{j i} & 0 & 0 & 0 & 0 & 0 & 0 & 0 \\ k_{\mathrm{A}-\mathrm{D}} & k_{\mathrm{B}-\mathrm{D}} & k_{\mathrm{C}-\mathrm{D}} & -\sum_{j=9}^{10} k_{j i} & k_{\mathrm{E}-\mathrm{D}} & 0 & k_{\mathrm{G}-\mathrm{D}} & k_{\mathrm{H}-\mathrm{D}} & 0 & 0 \\ k_{\mathrm{A}-\mathrm{E}} & k_{\mathrm{B}-\mathrm{E}} & 0 & 0 & -\sum_{j=4,6}^{9} k_{j i} & 0 & 0 & 0 & 0 & 0 \\ k_{\mathrm{A}-\mathrm{F}} & k_{\mathrm{B}-\mathrm{F}} & k_{\mathrm{C}-\mathrm{F}} & 0 & k_{\mathrm{E}-\mathrm{F}} & -\sum_{j=9} k_{j i} & 0 & 0 & 0 & 0 \\ k_{\mathrm{A}-\mathrm{G}} & k_{\mathrm{B}-\mathrm{G}} & k_{\mathrm{C}-\mathrm{G}} & 0 & k_{\mathrm{E}-\mathrm{G}} & 0 & -\sum_{j=4,8} k_{j i} & 0 & 0 & 0 \\ k_{\mathrm{A}-\mathrm{H}} & k_{\mathrm{B}-\mathrm{H}} & k_{\mathrm{C}-\mathrm{H}} & 0 & k_{\mathrm{E}-\mathrm{H}} & 0 & k_{\mathrm{G}-\mathrm{H}} & -\sum_{j=4,9} k_{j i} & 0 & 0 \\ k_{\mathrm{A}-\mathrm{I}} & k_{\mathrm{B}-\mathrm{I}} & k_{\mathrm{C}-\mathrm{I}} & k_{D-I} & k_{\mathrm{E}-\mathrm{I}} & k_{\mathrm{F}-\mathrm{I}} & k_{\mathrm{G}-\mathrm{I}} & k_{\mathrm{H}-\mathrm{I}} & 0 & 0 \\ k_{\mathrm{A}-\mathrm{J}} & k_{\mathrm{B}-\mathrm{J}} & 0 & k_{D-J} & 0 & 0 & 0 & 0 & 0 & 0\end{array}\right]$.


each lump, respectively). The coupled algorithm not only overcomes shortcomings of the Levenberg-Marquardt algorithm, which cannot jump out of local optimal solution and highly qualitative setting initial value, but also improves simulated annealing algorithm, where the searching efficiency gradually reduces.

\section{Materials and analysis of feeds and products}

The sample of atmospheric residue which was taken from an industrial TMP unit was used as feedstock; its properties are given in Table 2. The catalyst, called LTB-2, was used for maximizing propylene in the experiments. Its main physical properties are listed in Table 3.

In this study, all experiments were carried out in the XTL-5 typed riser unit [16]. The unit, similar to the commercial ones, includes a riser with stratified injections, a disengager, and a regenerator. The effluent from the top of the disengager goes into the condensing system, and the gas and liquid products were collected and measured, respectively. The resulting cracking gas was analyzed by a Varian 3800 gas chromatograph (GC). The liquid was fractionated to gasoline, diesel, and heavy oil by the true boiling point distillation. The mass percentage of gasoline, diesel, and heavy oil was analyzed and quantified with the Agilent 6890 N GC. The flue gas was measured during the reaction and then analyzed by the Varian GC3800 to determine the coke yield. More detailed information about

Table 2 Properties of atmospheric residue from Daqing refinery

\begin{tabular}{ll}
\hline Items & Values \\
\hline Density $\left(20^{\circ} \mathrm{C}\right)\left(\mathrm{g} \mathrm{cm}^{-3}\right)$ & 0.9052 \\
Viscosity $\left(80{ }^{\circ} \mathrm{C}\right)\left(\mathrm{mm}^{2} \mathrm{~s}^{-1}\right)$ & 78.84 \\
Carbon residue $(\%)$ & 5.31 \\
SARA $(\%)$ & \\
Saturates & 47.54 \\
Aromatics & 29.82 \\
Resins & 22.61 \\
Asphaltenes & 0.03 \\
Element composition $(\%)$ & \\
$\mathrm{C}$ & 85.21 \\
$\mathrm{H}$ & 12.59 \\
$\mathrm{~S}$ & 0.23 \\
$\mathrm{~N}$ & 0.31 \\
\hline
\end{tabular}

Table 3 Properties of LTB-2 catalyst

\begin{tabular}{lllll}
\hline $\begin{array}{l}\mathrm{W}\left(\mathrm{AL}_{2} \mathrm{O}_{3}\right) \\
(\%)\end{array}$ & $\begin{array}{l}V_{\mathrm{P}} \\
(\mathrm{ml} / \mathrm{g})\end{array}$ & $\begin{array}{l}S_{\mathrm{BET}} \\
\left(\mathrm{m}^{2} / \mathrm{g}\right)\end{array}$ & $\begin{array}{l}\text { Stack density } \\
\left(\mathrm{g} / \mathrm{cm}^{3}\right)\end{array}$ & $\begin{array}{l}\text { MAT } \\
\text { activity }\end{array}$ \\
\hline 48.6 & 0.26 & 211 & 0.74 & 64 \\
\hline
\end{tabular}

the experimental setup and operation procedures can be found in Ref. [16]. Twelve sets of experimental results data, including the operation conditions and product yield distributions, are given in Table 4.

\section{Results and discussion}

\section{Model parameters estimation and analysis}

Based on the twelve sets of experimental data, model parameters, including pre-exponential factors, activation energies and reaction rate constants under the temperature of $580{ }^{\circ} \mathrm{C}$, were estimated and calculated. The values of all these parameters are listed in Table 5.

The value of the activation energy reflects not only the degree of difficulty the reaction takes place in the riser reactor; it also embodies the sensitivity of the reaction to the reaction temperature [9]. According to Table 5, several conclusions can be deduced: (1) the activation energies of cracking heavy oil, diesel, gasoline and LPG increase sequentially, which indicates that the longer the carbon chain of the hydrocarbon is, the more readily it cracks. This agrees well with the carbonium ion mechanism in FCC processes; (2) the activation energy of producing low-carbon olefin from cracking gasoline olefins is a little smaller than that of producing low-carbon alkanes, and the energy barrier that needs to be crossed in reactions of cracking gasoline olefins is much higher than that in reactions of cracking gasoline saturates. The phenomena indicate that an improved yield of propylene would be obtained when gasoline which is rich in the olefins is fed into the riser. Indeed, $\mathrm{Li}$ [5] showed that light gasoline with a relative high content of olefins gives rise to a higher propylene yield than heavy oil and full-cut gasoline. This is consistent with the target of decreasing the content of olefins in gasoline and improving the yield of propylene with the second-stage riser reactor in the TMP process.

As shown in column 5 in Table 5, the reaction rate constants of propylene formation at $580{ }^{\circ} \mathrm{C}$ from cracking heavy oil, diesel, gasoline olefins, gasoline saturates and butylene decrease in turn. On one hand, this is in accordance with the catalytic reaction rules; on the other hand, it makes it clear that in the TMP technology, the $\mathrm{C}_{4}$ mixing gas and light gasoline should be fed into the riser reactor from the lower entrance, where the reaction condition is relatively rigorous and the conversions of short-chain light hydrocarbons would be enhanced.

\section{Verification of model parameters}

The ten-lump kinetic model and its kinetic parameters estimated by the coupled method are verified by the 
Table 4 Lump yield of TMP process

\begin{tabular}{|c|c|c|c|c|c|c|c|c|c|c|c|c|}
\hline Data set no. & 1 & 2 & 3 & 4 & 5 & 6 & 7 & 8 & 9 & 10 & 11 & 12 \\
\hline Reaction temperature $\left({ }^{\circ} \mathrm{C}\right)$ & 580 & 580 & 580 & 580 & 580 & 580 & 580 & 580 & 580 & 570 & 520 & 520 \\
\hline Catalyst-to-oil ratio & 11.11 & 10.98 & 11.01 & 11.0 & 11.14 & 10.92 & 11.06 & 11.02 & 11.09 & 8.43 & 7.74 & 8.15 \\
\hline Reaction time (s) & 0.91 & 1.26 & 1.29 & 1.32 & 1.36 & 1.42 & 1.44 & 1.64 & 1.83 & 1.46 & 1.26 & 1.26 \\
\hline \multicolumn{13}{|c|}{ Product yield distributions (\%) } \\
\hline Heavy oil & 11.2 & 7.84 & 9.61 & 9.08 & 8.96 & 8.05 & 11.42 & 6.39 & 5.68 & 10.15 & 19.41 & 23.49 \\
\hline Diesel oil & 13.19 & 10.2 & 11.39 & 11.12 & 10.79 & 10.82 & 10.79 & 9.88 & 8.65 & 11.71 & 13.25 & 12.87 \\
\hline Gasoline olefins & 12.58 & 11.81 & 12.66 & 12.44 & 13.37 & 12.57 & 11.56 & 11.29 & 10.9 & 12.07 & 11.77 & 10.53 \\
\hline Gasoline aromatics & 7.68 & 7.65 & 7.68 & 7.7 & 7.11 & 7.71 & 7.03 & 7.12 & 6.86 & 7.73 & 4.49 & 3.84 \\
\hline Gasoline saturates & 4.48 & 3.71 & 3.82 & 3.82 & 4.19 & 3.99 & 3.89 & 3.58 & 3.58 & 4.08 & 4.97 & 4.45 \\
\hline Butane + propane & 2.39 & 2.59 & 2.42 & 2.44 & 2.81 & 2.59 & 2.59 & 3.48 & 3.26 & 2.77 & 2.56 & 4.03 \\
\hline Butylene & 14.6 & 17.09 & 16.21 & 16.47 & 16.77 & 16.61 & 16.16 & 17.05 & 18.07 & 15.93 & 14.86 & 14.4 \\
\hline Propylene & 17.88 & 20.72 & 18.99 & 19.37 & 18.86 & 19.48 & 19.25 & 21.43 & 22.82 & 18.54 & 17.4 & 16.34 \\
\hline Dry gas & 9.71 & 11.16 & 9.8 & 10.04 & 10.12 & 10.44 & 10.7 & 12.43 & 13.25 & 9.92 & 5.53 & 5.29 \\
\hline Coke & 6.29 & 7.23 & 7.42 & 7.52 & 7.02 & 7.74 & 6.61 & 7.35 & 6.93 & 7.1 & 5.75 & 4.76 \\
\hline
\end{tabular}

Table 5 Kinetic parameters of the ten-lump kinetic model

\begin{tabular}{|c|c|c|c|c|}
\hline Path no. & Reaction path & $\begin{array}{l}\text { Pre-exponential } \\
\text { factor }\left(k_{0}\right), 1 / \mathrm{s}\end{array}$ & $\begin{array}{l}\text { Activation energy } \\
\left(E_{\mathrm{a}}\right), \mathrm{kJ} / \mathrm{mol}\end{array}$ & $\begin{array}{l}\text { Reaction rate constant } \\
\text { at } 580{ }^{\circ} \mathrm{C}(k), 1 / \mathrm{s}\end{array}$ \\
\hline 1 & $\mathrm{HO} \rightarrow \mathrm{DO}$ & 590.6 & 59.24 & 0.1394 \\
\hline 2 & $\mathrm{HO} \rightarrow \mathrm{GO}$ & $1.15 \mathrm{E}+04$ & 79.51 & 0.1559 \\
\hline 3 & $\mathrm{HO} \rightarrow \mathrm{GA}$ & $1.50 \mathrm{E}+06$ & 117.60 & 0.0947 \\
\hline 4 & $\mathrm{HO} \rightarrow \mathrm{GS}$ & 423.4 & 64.17 & 0.0499 \\
\hline 5 & $\mathrm{HO} \rightarrow \mathrm{C}_{3,4}$ & 0.5102 & 23.59 & 0.0183 \\
\hline 6 & $\mathrm{HO} \rightarrow \mathrm{C}_{4=}$ & 14.49 & 35.42 & 0.0983 \\
\hline 7 & $\mathrm{HO} \rightarrow \mathrm{C}_{3}=$ & 8.152 & 30.56 & 0.1097 \\
\hline 8 & $\mathrm{HO} \rightarrow \mathrm{DG}$ & $1.88 \mathrm{E}+03$ & 75.53 & 0.0447 \\
\hline 9 & $\mathrm{HO} \rightarrow \mathrm{CK}$ & 28.37 & 47.13 & 0.0369 \\
\hline 10 & $\mathrm{DO} \rightarrow \mathrm{GO}$ & $1.47 \mathrm{E}+03$ & 78.53 & 0.0229 \\
\hline 11 & $\mathrm{DO} \rightarrow \mathrm{GA}$ & $1.22 \mathrm{E}+05$ & 111.20 & 0.0190 \\
\hline 12 & $\mathrm{DO} \rightarrow \mathrm{GS}$ & 301.1 & 61.72 & 0.0501 \\
\hline 13 & $\mathrm{DO} \rightarrow \mathrm{C}_{3,4}$ & 2.808 & 31.96 & 0.0310 \\
\hline 14 & $\mathrm{DO} \rightarrow \mathrm{C}_{4=}$ & 335.9 & 61.72 & 0.0559 \\
\hline 15 & $\mathrm{DO} \rightarrow \mathrm{C}_{3}=$ & 638.4 & 63.86 & 0.0786 \\
\hline 16 & $\mathrm{DO} \rightarrow \mathrm{DG}$ & $1.65 \mathrm{E}+03$ & 75.23 & 0.0409 \\
\hline 17 & $\mathrm{DO} \rightarrow \mathrm{CK}$ & 242.5 & 65.16 & 0.0249 \\
\hline 18 & $\mathrm{GO} \rightarrow \mathrm{GA}$ & 80.22 & 79.11 & 0.0012 \\
\hline 19 & $\mathrm{GO} \rightarrow \mathrm{C}_{3,4}$ & 2.848 & 56.72 & 0.0010 \\
\hline 20 & $\mathrm{GO} \rightarrow \mathrm{C}_{4}=$ & 68.69 & 57.20 & 0.0216 \\
\hline 21 & $\mathrm{GO} \rightarrow \mathrm{C}_{3}=$ & 123.3 & 62.35 & 0.0188 \\
\hline 22 & $\mathrm{GO} \rightarrow \mathrm{DG}$ & 1.403 & 56.65 & 0.0005 \\
\hline 23 & $\mathrm{GA} \rightarrow \mathrm{DG}$ & 19.03 & 46.38 & 0.0275 \\
\hline 24 & $\mathrm{GA} \rightarrow \mathrm{CK}$ & 8.942 & 44.20 & 0.0176 \\
\hline 25 & $\mathrm{GS} \rightarrow \mathrm{GA}$ & 0.3332 & 33.88 & 0.0028 \\
\hline 26 & $\mathrm{GS} \rightarrow \mathrm{C}_{3,4}$ & 0.763 & 33.65 & 0.0066 \\
\hline 27 & $\mathrm{GS} \rightarrow \mathrm{C}_{4}=$ & 195.3 & 65.11 & 0.0202 \\
\hline 28 & $\mathrm{GS} \rightarrow \mathrm{C}_{3}=$ & 575 & 74.43 & 0.0159 \\
\hline 29 & $\mathrm{GS} \rightarrow \mathrm{DG}$ & 10.22 & 65.46 & 0.0011 \\
\hline 30 & $\mathrm{C}_{3,4} \rightarrow \mathrm{DG}$ & 614.6 & 73.51 & 0.0194 \\
\hline 31 & $\mathrm{C}_{4=} \rightarrow \mathrm{GA}$ & $6.85 \mathrm{E}+03$ & 93.28 & 0.0133 \\
\hline 32 & $\mathrm{C}_{4=} \rightarrow \mathrm{C}_{3=}$ & $2.13 \mathrm{E}+03$ & 90.51 & 0.0061 \\
\hline 33 & $\mathrm{C}_{4=} \rightarrow \mathrm{DG}$ & 745.4 & 72.17 & 0.0284 \\
\hline 34 & $\mathrm{C}_{3=} \rightarrow \mathrm{GA}$ & $6.40 \mathrm{E}+03$ & 93.87 & 0.0115 \\
\hline 35 & $\mathrm{C}_{3=} \rightarrow \mathrm{DG}$ & 746.6 & 83.10 & 0.0061 \\
\hline
\end{tabular}




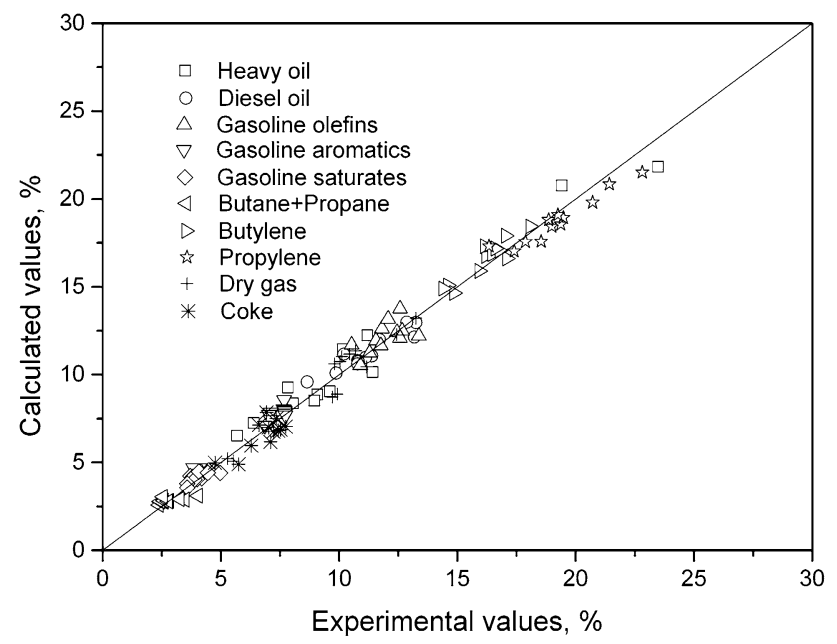

Fig. 2 The residual error between calculated and experimental value of ten-lump

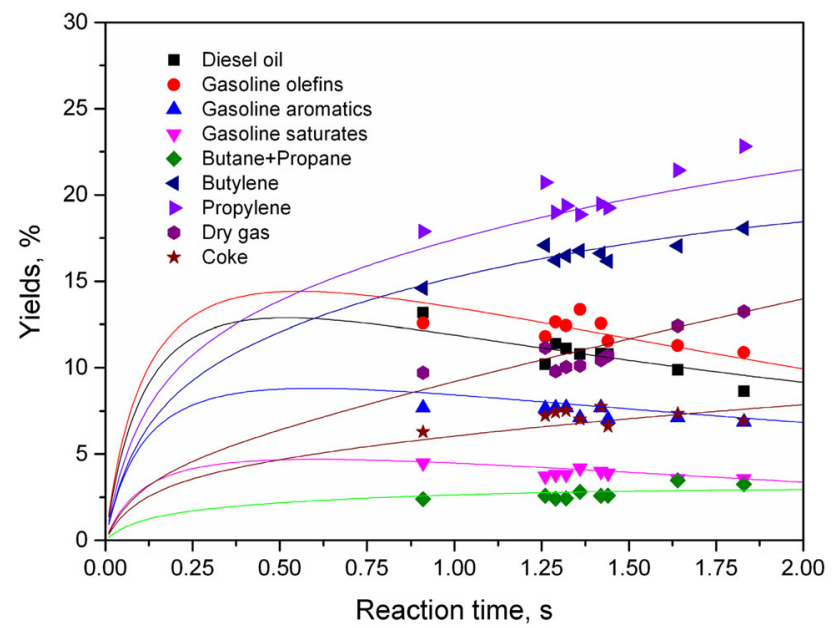

Fig. 3 Comparison between experimental yields and calculated yields at $580{ }^{\circ} \mathrm{C}$ for a single riser

experimental data. Figure 2 shows the comparison between experimental and predicted yields of the ten lumps at various operation conditions using the kinetic model proposed in this work. As observed in Fig. 2, the model predictions agree well with the experimental data, which indicates that the kinetic model is quite reasonable in a statistical test view.

Figure 3 shows the concentration profiles along the reaction time under the temperature of $580{ }^{\circ} \mathrm{C}$ in a single riser reactor. It can be observed from the Fig. 3 that the tenlump kinetic model predicts sufficiently well the experimental data and the variation tendency of product yields at different residence time.

Figure 4 shows the comparison between experimental yields [16] and calculated yields for two-stage riser. The

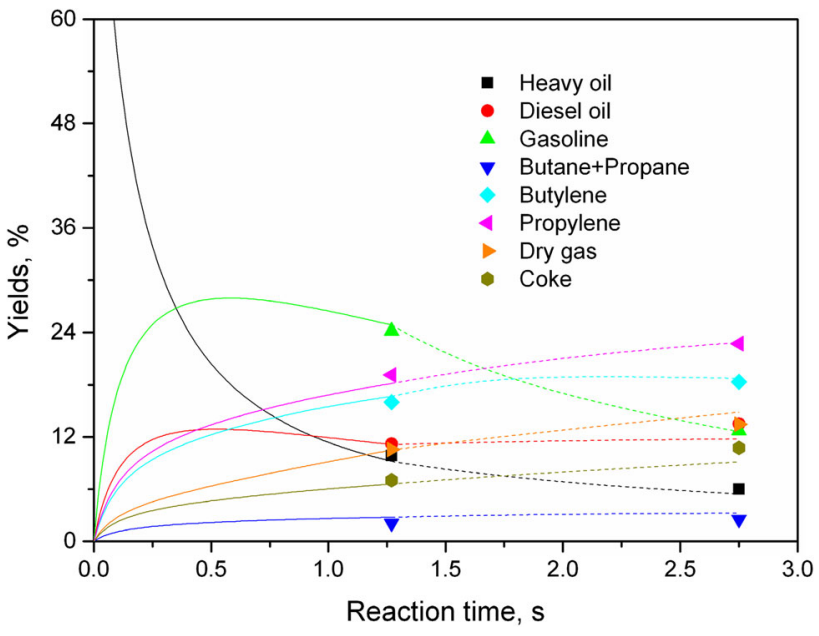

Fig. 4 Comparison between experimental yields and calculated yields for two-stage riser

solid line in Fig. 4 depicts the concentration profiles along the residence time in the first-stage riser, while the dot line represents the comprehensive predicted results for the twostage riser. The operational temperature in the first-stage riser is $580{ }^{\circ} \mathrm{C}$, the reaction time is $1.27 \mathrm{~s}$, and the RCO is 11.0. In the second-stage riser, the operational temperature is $600{ }^{\circ} \mathrm{C}$, the residence time is $1.48 \mathrm{~s}$, and the RCO is 13.0 or so. In the TMP technology, the cracking products from the first-stage riser enter a fractionator and are separated. The products of gas and diesel leave the reaction system, while the heavy cycle oil (HCO) and gasoline enter the second-stage riser and proceeds cracking reactions over regenerated catalysts. The two-stage riser results were obtained by the simulated calculation of two-time independent riser simulations. As can be observed, the model predictions show a quite convincing agreement with both the first-stage riser experimental data and the comprehensive two-stage riser data.

Figure 5 shows the comparison of the propylene yields at $580{ }^{\circ} \mathrm{C}$ predicted by Guo's 11-lump kinetic model [13] and the developed 10-lump kinetic model. It can be seen in Fig. 5 that the yields of propylene from both model predictions increase with the increase in conversion of heavy oil. However, when the conversion is greater than $98.5 \%$, the yield of propylene predicted by Guo's model continues increasing dramatically. Obviously, the tendency is not consistent with the catalytic reaction theories. According to the catalytic theory, propylene would be converted into dry gas and coke when the conversion approximates $100 \%$. As a result, the yield of propylene should decrease dramatically. The shift was exactly predicted using the proposed ten-lump model. Thereby, the reasonability of the ten-lump kinetic model was further verified. 


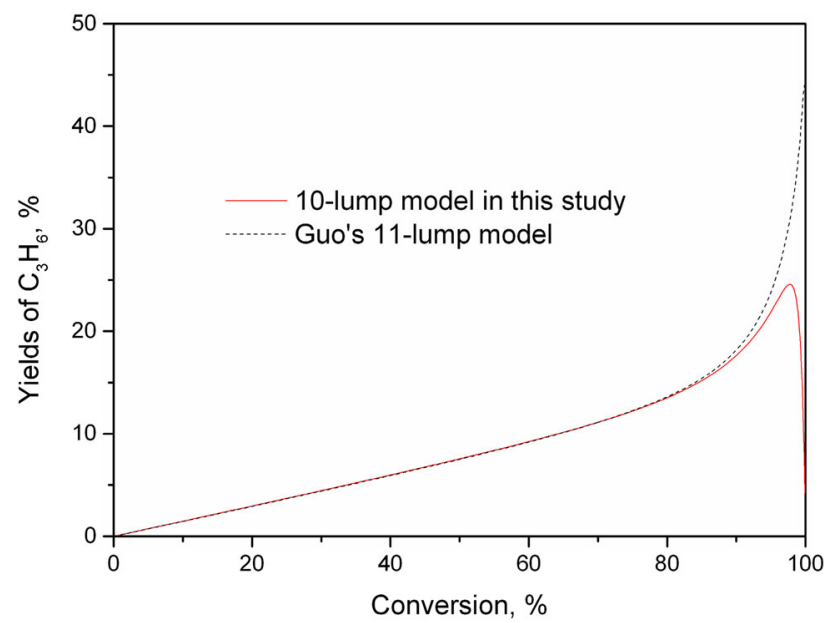

Fig. 5 Comparison of the propylene yields predicted by Guo's model and the proposed model

\section{Conclusions}

A novel ten-lump kinetic model for the TMP process has been proposed. According to the catalytic reaction mechanisms, the reaction system was divided into ten lumps by reasonably simplifying the reaction network, including heavy oil, diesel oil, gasoline olefins, gasoline aromatics, gasoline saturates, (butane + propane), butylene, propylene, dry gas and coke. Thirty-five sets of model parameters were estimated based on twelve sets of experimental data with the coupled SA-LM (Simulated Annealing and Levenberg-Marquardt) method. The findings indicate that the model could predict the riser key products and their compositions quite well; thereby it presents the possibility of being applied to the production practice for the TMP process.

Acknowledgments The authors are grateful to the National 973 Program of China (No. 2012CB215006) for the financial support.

Open Access This article is distributed under the terms of the Creative Commons Attribution 4.0 International License (http://creativecommons.org/licenses/by/4.0/), which permits unrestricted use, distribution, and reproduction in any medium, provided you give appropriate credit to the original author(s) and the source, provide a link to the Creative Commons license, and indicate if changes were made.

\section{References}

1. Zhong L, Huo Y, Wang J (1996) ARGG process for maximum gas plus gasoline production from atmospheric residue. Pet Process Petrochem 26(6):15-19

2. Wang L, Yang B, Wang G et al (2003) New FCC process minimizes gasoline olefin, increases propylene. Oil Gas J 101(6):52-58

3. Xie C (1997) Commercial application of deep catalytic cracking catalysts for production of light olefins. Petrochem Technol 26(12):825

4. Han W, Huang R, Gong J (2006) Commercial application of new FCC process-MIP-CGP. Pet Refin Eng 36(9):1

5. Li C, Yang C, Shan H (2007) Maximizing propylene yield by two-stage riser catalytic cracking of heavy oil. Ind Eng Chem Res 46(14):4914-4920

6. Yang C, Chen X, Zhang J et al (2014) Advances of two-stage riser catalytic cracking of heavy oil for maximizing propylene yield (TMP) process. Appl Petrochem Res 4(4):435-439

7. Pinheiro CI, Fernandes JL, Domingues L et al (2011) Fluid catalytic cracking (FCC) process modeling, simulation, and control. Ind Eng Chem Res 51(1):1-29

8. Du YP, Yang Q, Zhao H et al (2014) An integrated methodology for the modeling of Fluid Catalytic Cracking (FCC) riser reactor. Appl Petrochem Res 4(4):423-433

9. Wu F, Weng H, Luo S (2008) Kinetic model for heavy oil catalytic cracking in riser of FDFCC process. Acta Pet Sinica (Pet Process Sect) 24(5):540-547

10. Guo X, Long J, Hou S et al (2005) FCC reaction mechanism and kinetic modelling based on molecular description. Pet Process Petrochem 35(11):74-78

11. Xu Z (2008) Maximizing yield of propylene by two-stage riser catalytic pyrolysis technology. Tianjin University, Tianjin China

12. Liu Y (2008) Study on catalytic pyrolysis of FCC gasoline and kinetic model for the two-stage riser fluid catalytic cracking. China university of Petroleum (East China), Shandong China

13. Guo J (2008) Primary study on the lumped kinetic model for heavy oil cracking into propylene by two-stage-riser technology. China university of Petroleum (East China), Shandong China

14. Shan H, Dong H, Zhang J et al (2001) Experimental study of twostage riser FCC reactions. Fuel 80(8):1179-1185

15. Klepel O, Loubentsov A, Böhlmann W et al (2003) Oligomerization as an important step and side reaction for skeletal isomerization of linear butenes on H-ZSM-5. Appl Catal A 255(2):349-354

16. Liang Z (2008) Primary study on Two-stage riser catalytic pyrolysis of gas oil. China university of Petroleum (East China), Shandong China 